\title{
The Role of Endothelin and Endothelin Antagonists in Chronic Kidney Disease
}

\author{
Rupesh Raina ${ }^{a, b}$ Abigail Chauvin ${ }^{c}$ Ronith Chakraborty ${ }^{a}$ Nikhil Nair $^{d}$ \\ Haikoo Shah ${ }^{c}$ Vinod Krishnappa ${ }^{\text {a, }}$ Kirsten Kusumi ${ }^{b}$ \\ a Department of Nephrology, Cleveland Clinic Akron General/Akron Nephrology Associates, Akron, OH, USA; \\ ${ }^{\mathrm{b}}$ Akron Children's Hospital, Akron, OH, USA; ' Northeast Ohio Medical University, Rootstown, OH, USA; \\ ${ }^{\mathrm{d}}$ Case Western Reserve University, Cleveland, $\mathrm{OH}, \mathrm{USA}$
}

\section{Keywords}

Endothelin · Endothelin antagonists · Diabetic

nephropathy · Hypertensive nephropathy · Focal segmental glomerulosclerosis

\section{Abstract \\ Background: Endothelins (ET) are a family of peptides that act as potent vasoconstrictors and pro-fibrotic growth fac- tors. ET-1 is integral to renal and cardiovascular pathophysi- ology and exerts effects via autocrine, paracrine and endo- crine signaling pathways tied to regulation of aldosterone, catecholamines, and angiotensin. In the kidney, ET-1 is criti- cal to maintaining renal perfusion and controls glomerular arteriole tone and hemodynamics. It is hypothesized that ET-1 influences the progression of chronic kidney disease (CKD), and the objective of this review is to discuss the patho- physiology, and role of ET and endothelin receptor antago- nists (ERAs) in CKD. Summary: The use of ERAs in hyperten- sive nephropathy has the potential to decrease proteinuria, and in diabetic nephropathy has the potential to restore gly- cocalyx thickness, also decreasing proteinuria. Focal seg- mental glomerular sclerosis has no specific Food and Drug Administration-approved therapy currently, however, ERAs}

show promise in decreasing proteinuria and slowing tissue damage. ET-1 is a potential biomarker for autosomal dominant polycystic kidney disease progression and so it is thought that ERAs may be of some therapeutic benefit. Key Messages: Multiple studies have shown the utility of ERAs in CKD. These agents have shown to reduce blood pressure, proteinuria, and arterial stiffness. However, more clinical trials are needed, and the results of active or recently concluded studies are eagerly awaited.

(C) 2019 The Author(s) Published by S. Karger AG, Basel

\section{Introduction}

Endothelin (ET) is a 21 amino-acid peptide characterized in humans by 3 distinct genes with unique isoforms ET-1, ET-2, ET-3; all 3 are potent vasoconstrictors and pro-fibrotic growth factors 9 [1]. ET-1, however, is the predominant vascular isoform with the greatest regulatory effect on vascular tone and is integral in the regulation of renal and cardiovascular pathophysiology. ET-1 exerts effects via autocrine, paracrine and endocrine signaling pathways and regulates both catecholamines and the renin-angiotensin-aldosterone system (RAAS) $[2,3]$. 


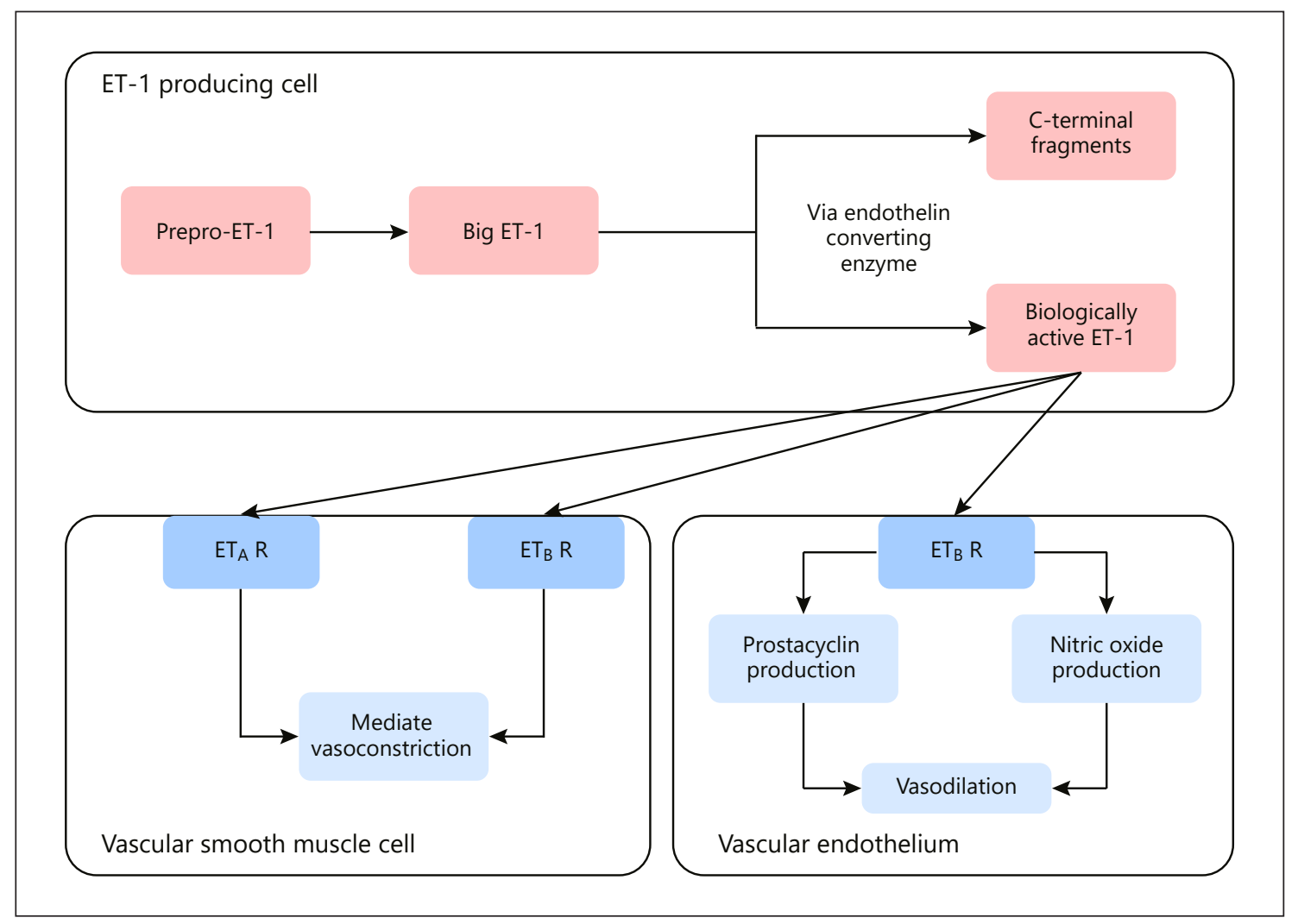

Fig. 1. Production and actions of ET-1 [7]. ET-1 begins as prepro-ET-1, is converted to big ET-1, and then ET converting enzyme cleaves it into the $\mathrm{C}$-terminal fragments and biologically active ET-1. Biologically active ET-1 then goes out to exert its effects on the body, mediated by $\mathrm{ET}_{\mathrm{A}}$ and $\mathrm{ET}_{\mathrm{B}}$ receptors. ET-1, endothelin-1; $\mathrm{ET}_{\mathrm{A}}$ endothelin $\mathrm{A} ; \mathrm{ET}_{\mathrm{B}}$, endothelin $\mathrm{B} ; \mathrm{ET}_{\mathrm{B}} \mathrm{R}, \mathrm{ET}_{\mathrm{B}}$ receptors.

ET-1 activation is mediated by endothelin converting enzymes, which cleave ET from its precursor protein bigET-1 into its biologically active component and C-terminal fragments [4-6]. Once activated, ET-1 has wide-ranging effects on multiple areas throughout the body, including vascular smooth muscle cells and endothelium (Fig. 1) [7]. ET-1 affects vascular smooth muscle cells following cellular uptake via clathrin-mediated endocytosis and is cleared by receptors in the lung and kidney [8-11]. ET synthesis is upregulated by gene transcription induced by angiotensin, vasopressin, interleukin-1, low extracellular $\mathrm{pH}$, and cyclosporine $\mathrm{A}$ and can be decreased by prostacyclin, nitric oxide (NO), and natriuretic peptides [12].

ET effects are moderated by the particular isoform produced as well as the method of action utilized (paracrine, autocrine or endocrine). In addition, the downstream effect of ET is also dependent on the $2 \mathrm{G}$ proteincoupled receptor isoforms $\left(\mathrm{ET}_{\mathrm{A}}\right.$ and $\left.\mathrm{ET}_{\mathrm{B}}\right)$. In the vasculature, binding of $\mathrm{ET}_{\mathrm{A}}$ triggers vasoconstriction and mitogenesis, leading to cellular and mesangial proliferation with fibrosis. Activation of $\mathrm{ET}_{\mathrm{A}}$ also releases adrenal catecholamines and increases inotropy, elevating blood pressure (Fig. 2) [2]. $\mathrm{ET}_{\mathrm{B}}$ activation exerts an anti-hypertensive effect via vasodilation from prostaglandin, NO, and natriuresis as well as anti-mitogenic effects, which inhibit cellular proliferation and inflammation (Fig. 2) $[13,14]$.

In the kidney, ET-1 is a stress-induced regulator produced by the vascular endothelium, mesangial cells, and tubular epithelium with the greatest amount of activity expressed by principal cells in the medullary collecting duct [15]. ET activation can escalate progression of chronic kidney disease (CKD) via ET-1 and $\mathrm{ET}_{\mathrm{A}}$ mediated pro-fibrotic pathways, playing a role in diseases such as diabetic nephropathy (DN), hypertensive nephropathy, focal segmental glomerular sclerosis (FSGS), and autosomal dominant polycystic kidney disease (ADPKD) [16]. Early data suggest that antagonizing ET may be a promising therapeutic avenue. Preclinical and early phase clinical 


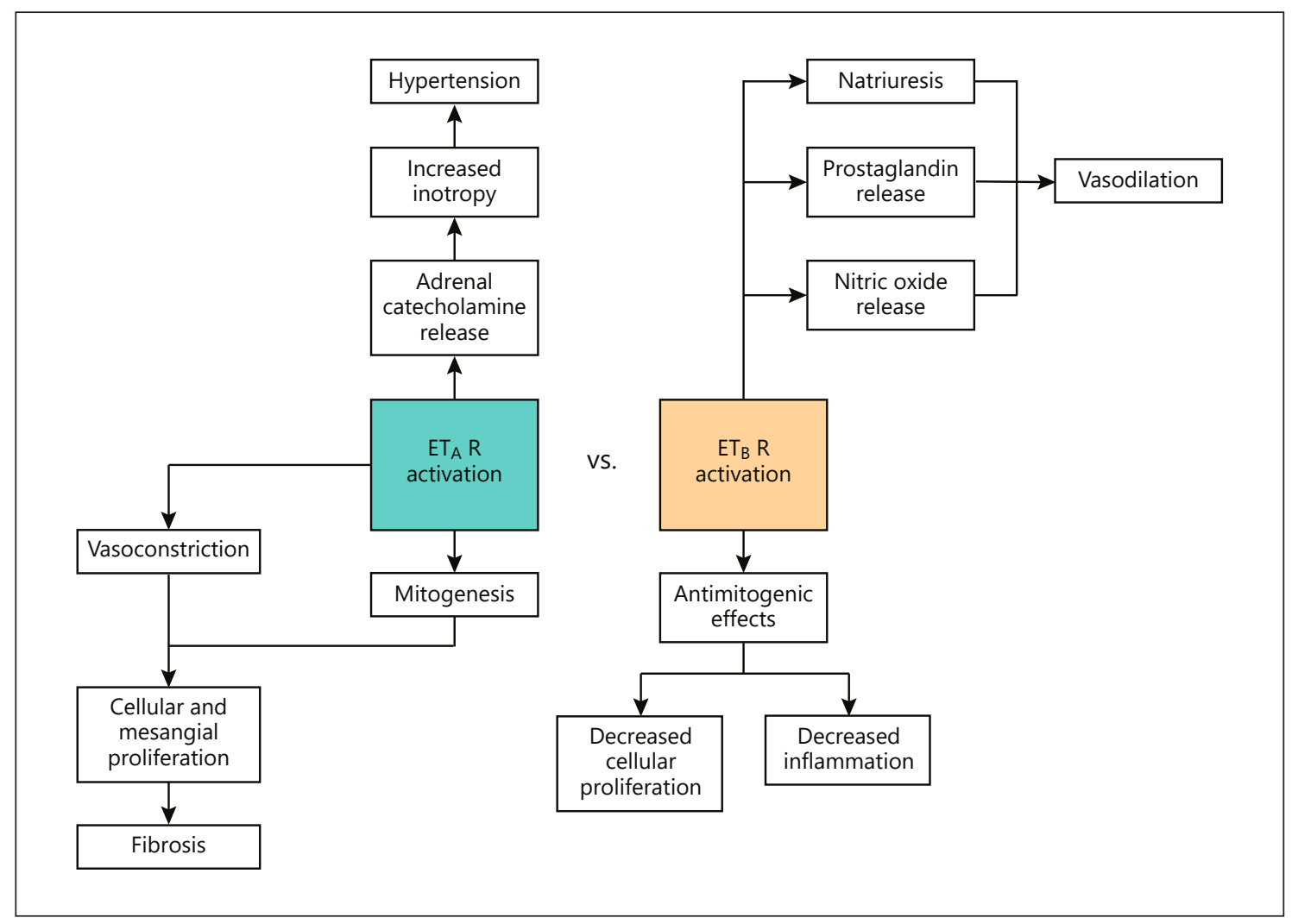

Fig. 2. Effects of $E T_{A}$ versus $E T_{B}$ activation. This figure demonstrates the different downstream effects of $E T_{A} R$ and $\mathrm{ET}_{\mathrm{B}} \mathrm{R}$ activation via $\mathrm{ET}-1$. $\mathrm{ET}$, endothelin; $\mathrm{ET}_{\mathrm{A}} \mathrm{R}, \mathrm{ET}_{\mathrm{A}}$ receptor; $\mathrm{ET}_{\mathrm{B}} \mathrm{R}, \mathrm{ET}_{\mathrm{B}}$ receptor.

studies indicate that ET antagonists may delay glomerular injury, podocyte effacement, proteinuria, and eventual scarring and sclerosis. This article will provide a comprehensive review regarding the role of ET in renal pathophysiology and specifically CKD. PubMed/Medline was searched for relevant articles using keywords "chronic kidney disease," "CKD," "endothelin," "ET-1," "endothelin antagonist," "diabetic nephropathy," "hypertensive nephropathy," "focal segmental glomerular sclerosis," and "autosomal dominant polycystic kidney disease," and "ADPKD." Additionally, Clinicaltrials.gov was searched for recent/current clinical trials pertaining to ET and CKD.

\section{ET and Renal Function}

ET has widespread effects including regulation of blood pressure, modifying cardiac output, altering systemic vascular resistance, as well as modulation of central and peripheral nervous system activity [2]. ET- 1 is critical to maintaining renal perfusion and influences glomerular arteriole tone and hemodynamics; endogenous renal ET-1 is also integral to fluid and sodium homeostasis [2]. ET's final downstream effects can be oppositional and are mediated by the receptor isoform bound. In the renal cortex, ET-1 binding of $\mathrm{ET}_{\mathrm{A}}$ drives afferent vasoconstriction decreasing renal blood flow and glomerular filtration rate (GFR). Additionally, ET-1 binding of $\mathrm{ET}_{\mathrm{A}}$ has proinflammatory and sclerotic effects on the kidney and research has shown increased transgenic expression of ET-1 in rats promotes renal scarring, increasing interstitial fibrosis and glomerulosclerosis $[1,17-20]$.

Alternatively, $\mathrm{ET}_{\mathrm{B}}$ receptors $\left(\mathrm{ET}_{\mathrm{B}} \mathrm{R}\right)$ are expressed by the endothelial cells of the vasa recta and afferent arterioles where increased circulating volume-activated production of ET-1 and binding of $\mathrm{ET}_{\mathrm{B}} \mathrm{Rs}$ initiates vasodilation via $\mathrm{NO}$ production, leading to greater perfusion of the renal medulla, decreased sodium reabsorption and natriuresis [14]. Research has shown that knockout of both $\mathrm{ET}_{\mathrm{A}} \mathrm{R}$ and $\mathrm{ET}_{\mathrm{B}} \mathrm{R}$ in murine collecting ducts leads to worsened hypertension as well as salt retention when compared to mice with only $\mathrm{ET}_{\mathrm{B}} \mathrm{R}$ removed $[21,22]$. 


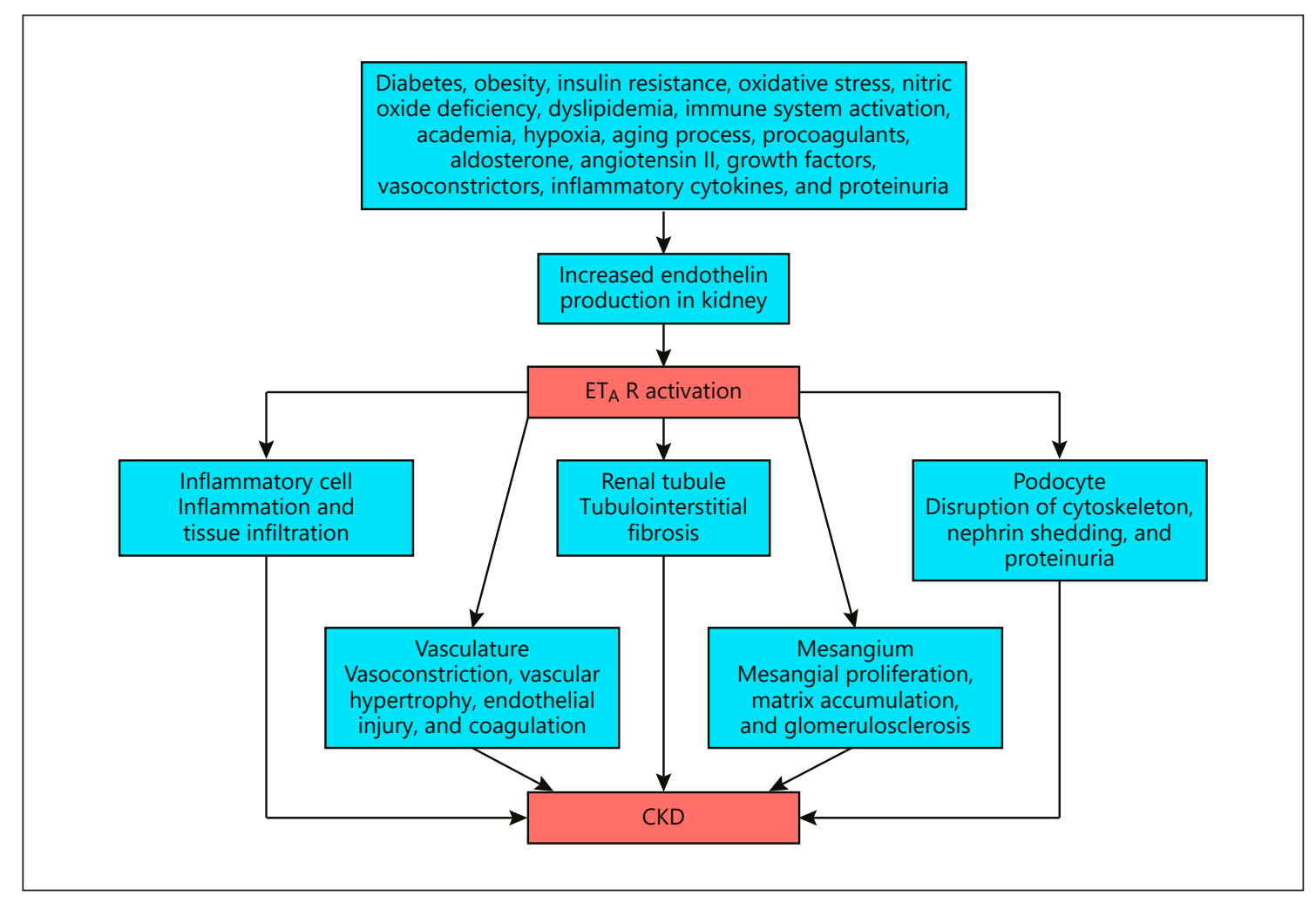

Fig. 3. Various mechanisms involved in the causation of CKD by ET-1 [31]. $\mathrm{ET}_{\mathrm{A}}$ endothelin $\mathrm{A}$; CKD, chronic kidney disease; $\mathrm{ET}_{\mathrm{A}} \mathrm{R}, \mathrm{ET}_{\mathrm{A}}$ receptor.

There is conflicting evidence as to whether sodium transport in the proximal tubule is affected by ET [2]. However, in the medullary thick ascending limb of loop of Henle, ET-1 inhibits movement of chloride and indirectly contributes to natriuresis $[7,23,24]$. The collecting duct produces the highest levels of ET-1 in the kidney and is also the area with the highest concentration of ET receptors, with $\mathrm{ET}_{\mathrm{B}}$ as the dominant receptor in the collecting duct and renal medulla overall [2, 25-30]. In mice, knockout of collecting duct ET-1 impaired sodium excretion, suggesting that ET-1 plays a crucial role in sodium regulation $[2,31]$. This process results in diuresis via prevention of sodium and thus water reabsorption, most particularly in the collecting duct due to its high concentration of $\mathrm{ET}_{\mathrm{B}}[2,8,9]$. This experimental evidence suggests that ET-1 is necessary for routine regulation of sodium and fluid balance throughout the nephron. Loss of renal control over sodium and fluid homeostasis curtails the kidneys ability to compensate for changes in volume status and can negatively impact renal function

\section{Role of ET in CKD}

Glomerular injury and scarring is the hallmark of CKD progression regardless of the underlying disease and increased production of ET- 1 has been found in multiple diseases associated with CKD including diabetes and insulin resistance, obesity, and dyslipidemia [10,31], Renal ET-1 production is also increased by the aging process, growth factors, inflammatory cytokines, and proteinuria [31]. Schematic representation of various mechanisms by which ET-1 is involved in the causation of CKD by increased ET-1 production can be found in Figure 3. ET-1 binding of $\mathrm{ET}_{\mathrm{A}}$ stimulates renal fibroblasts, driving increased extracellular matrix synthesis, inducing collagen production, and mesangial cell proliferation with the secretion of fibronectin and type IV collagen furthering scar formation $[10,11]$. Systemic acidification stimulates renal ET-1 production, leading to acid secretion in the proximal and distal nephron as a compensatory response. Progressive renal dysfunction further worsens metabolic acidosis and ET-1 secretion contributes to $\mathrm{CKD}$ progression via ET-1 and $\mathrm{ET}_{\mathrm{A}}$ mediated pro- 
fibrotic pathways [16]. Furthermore, studies have demonstrated the potent vasoconstrictive effect of ET-1 on renal vascular beds. Exogenous ET-1 has resulted in decreased GFR, increased filtration fraction, as well as sodium and fluid retention [32, 33].

Recently, stress of the endoplasmic reticulum (ER) has been proposed as a mechanism of ET-1 mediated renal tubular damage. Unfolded proteins accumulate in the ER, triggering the unfolded protein response (UPR). The UPR of the ER limits transcription and translation of proteins and upregulates ER chaperone expression in an attempt to fold the proteins already collected. Over time, this pathway can lead to organ damage and cell death, as is thought to be the case in renal disease [24, 35]. Research has shown an increase in both ET-1 and ER stress in renal diseases, such as DN and acute kidney injury due to contrast, ischemia/reperfusion, or septic shock [36-44]. At this time, it is unclear whether the ET-1 upregulates the UPR or vice versa [36].

\section{ET and E-Receptor Antagonists in DN}

$\mathrm{DN}$ is one of the leading causes of CKD and end-stage renal disease (ESRD) worldwide [45]. One in 3 diabetic patients will develop DN, a disease characterized by glomerular podocyte damage with glomerular proteinuria, loss of glomerular basement membrane integrity, increased mesangial cellularity, and tubular-interstitial sclerosis [46]. Progressive glomerular damage from diabetes is augmented by ET-1 production; hyperglycemia induces ET-1, which directly degrades podocytes' cytoskeleton leading to cellular apoptosis and podocyte effacement $[47,48]$. Via upregulated $\mathrm{ET}_{\mathrm{A}}$ receptors, the $\mathrm{ET}_{\mathrm{A}}$-receptor/ $\beta$-arrestin-1/Src-kinase complex is formed. This leads to the phosphorylation of $\beta$-catenin, increased Snail (family of zinc- finger transcription factors with a role in epithelial-mesenchymal transition [EMT]) expression and transactivation of epidermal growth factor receptor, which all contribute to podocyte damage [34, $49,50]$. Additionally, podocytes express ET receptors which when bound to ET-1 cause intracellular levels of calcium to quickly rise, influencing proliferation and signal transduction $[14,51]$. ET-enhanced glomerular damage has been demonstrated in multiple animal models including the positive linear increase of ET-1 mRNA with progressive DN in rats. Well-described inflammatory mediators, including TNF- $\alpha$ and reactive oxygen species (ROS), have also been positively correlated with ET-1 mRNA in diabetic mice [52]. In a streptozotocin (STZ) induced type 1 diabetes rat model, antagonism of the ET system reduced renal damage from DN [53]. Further- more, $\mathrm{ET}_{\mathrm{A}} \mathrm{R}$ and $\mathrm{ET}_{\mathrm{B}} \mathrm{R}$ were greatly overexpressed in the renal cortex of rats with STZ induced diabetes [14].

Antagonism of ET has also improved outcomes in human studies; atrasentan, an $\mathrm{ET}_{\mathrm{A}}$ antagonist, reduced albuminuria in patients with $\mathrm{DN}$ [54]. Withdrawal of atrasentan returned albuminuria to baseline. Unfortunately, due to the widespread physiological activity of ET across multiple organ systems, ET inhibition produces significant side effects and severely restricts individuals eligible for treatment and limits its clinical usefulness. For example, $\mathrm{ET}_{\mathrm{A}}$ antagonists have been contraindicated in patients with brain natriuretic peptide $>200 \mathrm{pg} / \mathrm{mL}$, history of heart failure, severe edema, or acute decrease in estimated GFR (eGFR) [54]. However, careful patient selection and use of diuretics may make ET inhibitors useful in CKD.

$\mathrm{ET}_{\mathrm{A}}$ antagonists can also improve glomerular permeability through non-hemodynamic mechanisms including improved glomerular glycocalyx production $[45,55]$. The glomerular glycocalyx is a glycoprotein coating on the luminal surface of glomerular capillaries that is necessary for maintaining capillary integrity. Boels et al. [55] utilized apolipoprotein E deficient mice as a model as their renovascular damage, high blood glucose, and hyperlipidemia closely replicate the phenotype of metabolic syndrome. Intraperitoneal injections of STZ were given to induce DN $[45,55]$. Researchers have found that ET-1 signals increased heparanase in podocytes, an enzyme that degrades heparan sulfate glycosaminoglycans: the major constituent of glycocalyx. This led to renal damage and proteinuria, as the glomerular glycocalyx could no longer function properly $[56,57]$. Mice given atrasentan had significantly reduced murine heparanase expression and demonstrated increased glomerular glycocalyx levels compared to controls [55]. In vitro studies of human umbilical vein endothelial cells showed decreased capillary glycocalyx thickness after incubation in the serum of uncontrolled diabetics. Adding atrasentan to the cell culture with diabetic human serum resulted in the restoration of glycocalyx thickness [55]. These results suggest that ET plays a critical role in the progression of $\mathrm{DN}$, as antagonizing ET receptors restored glycocalyx thickness.

Tubulointerstitial fibrosis (TIF) is a common endpoint of many kidney diseases including CKD and DN. Central to TIF is epithelial cells transition into the mesenchymal phenotype, a process known as EMT. During EMT, cell junctions are lost and collagen synthesis is diminished. EMT has been found to be essential during processes such as fibrosis, cancer development, and wound healing. Additionally, matrix metallopeptidase 9 
activation contributes to loss of epithelial cell junctions, disrupting the epithelial cell membrane and furthering the EMT process. Contraction of the cytoskeleton and cell motility is initiated by phosphorylation of MYPT-1, a member of the ET-1 mediating the RhoA/ROCK pathway. Lastly, blockage of phosphorylation of Yes-associated protein leads to increased transcription of mesenchymal cell markers such as aSMA. All of these aspects of EMT combined with the addition of collagen lead to tubule-interstitial fibrosis [58]. In rat studies, renal tubular epithelial cells underwent EMT in the presence of hyperglycemia; this may in part be due to the high ET-1 secretion triggered by high glucose levels [58]. Seccia et al. [58] suggest that the predominant ET receptor mediating the pathway of EMT is the $\mathrm{ET}_{\mathrm{B}} \mathrm{R}$ on proximal renal tubular cells. $\mathrm{ET}_{\mathrm{B}} \mathrm{R}$ is mostly located on endothelial cells and induces the release of $\mathrm{NO}$ and prostacyclin upon activation, resulting in vasodilation [59]. ET-1 binding of $\mathrm{ET}_{\mathrm{B}} \mathrm{R}$ results in decreased epithelial cells markers such as E-cadherin, while mesenchymal cell markers aSMA and vimentin increase. The role of the $\mathrm{ET}_{\mathrm{A}} \mathrm{R}$ in this process is unclear at this time [58].

\section{ET and Endothelin Receptor Antagonists in} Hypertensive Nephropathy

Hypertension is the second leading cause of ESRD in the United States, second only to diabetes [60]. Renal damage caused by hypertension is multifactorial and in part driven by the interplay of the RAAS and ET. Angiotensin II triggers the release of aldosterone from the adrenal cortex, which in turn increases renal ET-1 expression. Angiotensin II also directly triggers the contraction of the vascular smooth muscle of both afferent and efferent arterioles. This eventually leads to decreased renal blood flow, as well as glomerular capillary hypertension [60]. Angiotensin II also induces nicotinamide adenine dinucleotide phosphate oxidase in vascular smooth muscle cells, which drives production of ROS and increases ET-1 expression in the kidneys. ET-1 constriction of the cortex and medullary vasculature further worsens renal blood flow and promotes renal fibrosis as previously discussed. ROS production contributes to increasing arteriolar tone by decreasing $\mathrm{NO}$ levels and is also pro-fibrotic [60].

Currently, RAAS inhibitors are the first-line therapy for hypertensive nephropathy [60]. By inhibiting activation of angiotensin I to angiotensin II, RAAS inhibitors cut off the cytokine cascade before it amplifies resulting in improved blood pressure, decreased proteinuria, and limiting renal fibrosis [60]. Kimura et al. [61] induced hyper- tension in rats by giving deoxycorticosterone acetate (DOCA)-salt. The rats had their right kidney removed, and were randomly divided into 4 treatment groups: (1) DOCA-salt only, (2) nitrogen oxide synthase inhibitor $\mathrm{N} \omega$-nitro-L-arginine (NOARG) with DOCA-salt, (3) $\mathrm{ET}_{\mathrm{A}}$ selective receptor antagonist $\mathrm{ABT}-627, \mathrm{DOCA}$-salt and NOARG, and (4) DOCA-salt, NOARG, and nuclear factor kappa B (NF-kB) inhibitor pyrrolidinedithiocarbamate. Rats in group 2 developed the more severe renal disease compared to DOCA-salt treatment only. Nitrogen oxide synthase blockade activates NF- $\mathrm{kB}$, which is genetically upstream from ET-1. Thus, upregulation of NF-kB increases ET- 1 and t potentiates negative renal effects. In group 3, antagonism of ET-1 prevented all kidney damage and malfunction. In group 4, pyrrolidinedithiocarbamate usage decreased NF-kB activation, renal injury, and excess ET-1 synthesis. These results imply that the NF-kB/ET-1/ $\mathrm{ET}_{\mathrm{A}}$ pathway is a major mechanism for hypertensive renal damage [61]. Additional evidence comes from a transgenic rat model of hypertension where avosentan, an $\mathrm{ET}_{\mathrm{A}}$ receptor antagonist, was beneficial in decreasing albuminuria and mortality rates compared to control rats. Furthermore, dual therapy with endothelin receptor antagonist (ERA) and valsartan (angiotensin AT1 receptor antagonist) improved outcomes compared to treatment with ERAs or valsartan alone in this rat model [62].

Despite the promising research pointing to ERAs as a possible therapeutic option in hypertensive nephropathy, the side effect profile of ERAs must be considered before clinical application. The "ASCEND" trial tested the ERA, avosentan, and was halted prior to completion due to fluid retention leading to congestive heart failure and pulmonary edema [63, 64]. Baltatu et al. [62] sought to discover whether avosentan could be useful in the treatment of hypertensive nephropathy at lower dosages in transgenic rats in hopes of limiting fluid overload. It was found that only the avosentan at the highest dose $(100 \mathrm{mg} / \mathrm{kg})$ caused the fluid overload, while the decrease in blood pressure was approximately equivalent to the change observed at the second highest dose $(10 \mathrm{mg} / \mathrm{kg})$ [62]. Rats receiving no treatment experienced a $100 \%$ mortality rate. In contrast, survival rates of transgenic rats being treated with avosentan alone as well as rats receiving both avosentan and valsartan (an angiotensin AT1 receptor antagonist) were 55.6 and $85.7 \%$ respectively [62].

\section{ET and ERAs in FSGS}

FSGS is a podocytopathy characterized by scarring and fibrosis of segments of glomeruli and is a significant cause of proteinuria, CKD and ESRD in the United States [65]. 
Primary FSGS is rare in adults and accounts for 5\% of ESRD cases [65]. FSGS is more common in children, but the exact incidence is not well known. Previous studies estimated a pediatric incidence of $6.9 \%$, but more recent studies have found rates up to $23 \%$ [66]. The molecular mechanisms driving the development of FSGS are also not completely understood. Genetic mutations of structural proteins vital to podocyte architecture and function are associated with primary FSGS [67]. Alternative mechanisms include circulating factors, which damage podocytes with loss glomerular basement protein integrity and subsequent proteinuria [68]. ET has been a candidate protein and has been shown to cause pathologic changes in podocytes similar to those seen in FSGS [50]. Cultured podocytes treated with ET-1 lost cell markers indicative of podocytes including synaptopodin and acquired mesenchymal cell markers, such as aSMA. This cellular transition is similar to the EMT seen in TIF [50]. Daehn et al. [69] demonstrated that increased production of ET in FSGS also damages podocytes through oxidative stress with the injury of glomerular endothelial cells' mitochondria and promotes adjacent podocyte apoptosis.

Despite the morbidity of FSGS, there has yet to be a specific treatment approved by the Food and Drug Administration in the United States. Therefore, the primary goal of FSGS treatment is to decrease proteinuria and first-line therapy includes a combination of corticosteroids and ACE inhibitors or angiotensin receptor blockers (ARB). Second-line therapy includes calcineurin inhibition, typically with cyclosporine or tacrolimus [70]. Antagonizing the ET system has shown promise for decreasing proteinuria and slowing renal damage in FSGS. Buelli et al. [50] utilized the Adriamycin-induced FSGS murine model and found that these mice characteristically demonstrate an elevated renal ET-1 with parietal epithelial cells activation, pseudo-crescents formation, and eventually, Adriamycin-induced injury with progression to glomerular sclerosis. Treatment with ERAs mitigated cellular injury and inflammation with significantly improved renal function in these mice.

\section{ET and ERAs in ADPKD}

ADPKD is a disease of autosomal dominant inheritance that consists of prolific renal cyst formation that interferes with normal renal function [71]. Incidence is estimated to range between 1:400 and 1:1,000, thus rating as one of the most commonly inherited renal disorders [72]. ET-1 is integral to cyst development and fibrotic progression of ADPKD $[20,73]$. ET-1 effect on renal dysfunction in ADPKD is mediated in 3 main areas. First,
ET-1 modulates gene expression in response to glomerular and tubule injury by stimulating interstitial fibroblasts to express type I collagen and smooth muscle actin. Renal cyst formation and glomerular fibrosis have thus resulted from transgenic overexpression of ET-1 in murine studies. Second, ET and its receptors are increased in ADPKD affected kidneys. In mice, $\mathrm{ET}_{\mathrm{A}} \mathrm{mRNA}$ is increased 5-10 times in ADPKD kidneys vs. healthy controls [74]. Research suggests that as kidney disease progresses and function decreases, urinary ET-1 is increased [32, 75]. Human ADPKD patients have increased ET-1 levels in cyst walls and fluid; furthermore, urinary levels of ET-1 are higher in ADPKD patients compared to controls [76, 77].

The association of ET with ADPKD could mechanistically be linked through hypertension, given ET's many regulatory effects on renal and systemic blood pressure. However, Merta et al. [78] demonstrated that ET-1 and NO levels were significantly elevated in ADPKD patients vs. controls. Furthermore, there was no difference in ET-1 or NO levels when comparing normotensive to hypertensive ADPKD patients. This suggests that increased ET levels in ADPKD are independent of arterial hypertension [78]. Additional data suggested that imbalance between $\mathrm{ET}_{\mathrm{A}} \mathrm{R}$ and $\mathrm{ET}_{\mathrm{B}} \mathrm{Rs}$ may be implicated in $\mathrm{ET}$ and disease pathogenesis of ADPKD [74]. One human study found the upregulation of $\mathrm{ET}_{\mathrm{A}}$ receptors in renal arteries, glomeruli, and cystic epithelial cells in ADPKD patients but no significant difference in $\mathrm{ET}_{\mathrm{B}} \mathrm{R}$ levels compared to controls. Furthermore, there is evidence that ET receptors have different effects and Chang et al. [79] demonstrated that $\mathrm{ET}_{\mathrm{B}}$ blockade accelerated cystic disease progression while $\mathrm{ET}_{\mathrm{A}}$ blockade leads to tubular cell proliferation.

Current treatment for ADPKD centers on symptom reduction and slowing disease progression [80]. Targeted medication includes sirolimus (mTOR inhibitor), octreotide (a somatostatin analog), and/or tolvaptan (a selective vasopressin V2 receptor antagonist) [81]. Sirolimus and similar drug everolimus have been shown to decrease the rate at which total kidney volume (TKV) increases, however current evidence suggests they do not slow disease progression and renal damage as measured by eGFR [8183]. Octreotide also slows increasing TKV, but like sirolimus, it has no effect on decreasing renal function [81, 84-86]. Tolvaptan has also been shown to slow increasing TKV and Torres et al. [87] demonstrated a significant reduction in loss of kidney function vs. placebo, with declining kidney function measured as a $25 \%$ decrease in the reciprocal serum creatinine level [81].
Raina/Chauvin/Chakraborty/Nair/Shah/ Krishnappa/Kusumi 
ET-1 also has utility as a noninvasive biomarker to identify disease progression in high-risk ADPKD patients. This is especially useful since disease markers such as eGFR do not change until significant renal damage has already occurred [77, 88]. Raina et al. [77] found that urinary ET-1 positively correlated with TKV, which serves as a marker for cyst enlargement $(r=0.426)$, however, this correlation was not statistically significant $(p=0.1)$ and warrants further clinical investigation.

\section{Clinical Trials Evaluating ERAs for CKD Management}

All the available clinical trials involving ERAs for CKD management are summarized in Table 1 . In a study by Kohan et al. [89], it was found that atrasentan at doses of $0.75 \mathrm{mg}$ and $1.75 \mathrm{mg} /$ day significantly improved residual albuminuria in type II diabetes mellitus patients who were already on renin-angiotensin system blockers. Short-term results of the ASCEND study investigating the effect of ERA, avosentan, on progression of overt DN showed that avosentan significantly reduced albuminuria when added to renin-angiotensin system blockers. However, the trial was terminated prematurely after a median follow-up of 4 months due to higher cardiovascular adverse events, including fluid overload, congestive heart failure, and death [64].

The "Study of DN with Atrasentan" (SONAR) phase III trial was meant to determine the efficacy of atrasentan (an ERA) to treat type II DN and delay progression of kidney disease by decreasing the urine albumin-to-creatinine ratio (UACR) [90]. This trial was different than ASCEND and similar studies as it utilized a response enrichment design, where the trial only included patients likely to benefit from the experiment. Subjects included in the trial went through a Run-In Period to optimize RAS inhibitor dosage followed with the enrichment period with atrasentan to determine UACR. Afterwards, responders and nonresponders were included in a double-blind treatment period $[91,92]$. However, AbbVie terminated this study in 2018 due to lower than expected renal end points; not due to any safety concerns for the participants [93]. Another study that was meant to test the renoprotective effect of ERA, bosentan, was terminated due to problems in recruitment [94]. Lin et al. [95] investigated the effect of atrasentan in DN and found that up to $46 \%$ reduction in UACR can be attained without having a significant difference in the adverse effect of peripheral edema compared to controls. Further, Webb et al. [96] investigated whether changes in thoracic bioimpedance can serve as an indica- tor of fluid retention secondary to atrasentan in $\mathrm{DN}$ patients. Thoracic bioimpedance measurement has its application in congestive heart failure, as decreased thoracic bioimpedance is a sensitive indicator of pulmonary congestion even before the development of heart failure. However, in this study by Webb et al. [96], no correlation was found between thoracic bioimpedance and edema or weight gain in patients on atrasentan therapy.

A phase 2 study evaluating the efficacy and safety of sparsentan in FSGS patients (DUET study) was done to evaluate if first-in-class sparsentan decreased proteinuria in primary FSGS patients compared to ARB (irbesartan) treatment alone [97]. Sparsentan functions as both an $\mathrm{ET}_{\mathrm{A}}$ receptor antagonist and an angiotensin 1 receptor blocker. Patients were divided into 2 treatment arms: those receiving $300 \mathrm{mg}$ of irbesartan once daily, and those receiving oral sparsentan $(200,400$, or $800 \mathrm{mg})$ once daily [97]. The results of the study showed that the 8-week course of sparsentan was safe, well tolerated and resulted in significant reduction in proteinuria compared to irbesartan [97]. Dhaun et al. [98] evaluated the effect of ERA, sitaxsentan, in nondiabetic proteinuric CKD patients and found that the drug significantly decreased 24 -h proteinuria, protein: creatinine ratio, blood pressure, and pulse wave velocity compared to placebo.

Another study was the "Zibotentan Better Renal Scleroderma Outcome Study", which ran from October 2014 to 2017 per ClinicalTrials.gov. Zibotentan Better Renal Scleroderma Outcome Study was a phase II investigation of zibotentan, an ERA, and its effect on the progression of kidney disease due to scleroderma. The primary outcome measurement was soluble vascular cell adhesion molecule 1 level, which are reflective of renal involvement in scleroderma. Whether these levels were measured via the blood or the urine is unclear and the results of the study have not yet been published [99]. A different study by Bérézne et al. [100] tested the effect of bosentan in scleroderma renal crisis patients and found no improvement in renal outcomes.

\section{Side Effects of ERAs}

The side effect profile of ERAs is substantial and may limit their clinical usefulness. The most common adverse effect among ET blockers is fluid retention, which is due to $\mathrm{ET}_{\mathrm{B}} / \mathrm{ET}_{\mathrm{A}}$ blockade. This blockade leads to a decrease in $\mathrm{NO}$ and $\mathrm{PGE}_{2}$ causing an increase in sodium and water reabsorption. "Dual" antagonists have an $\mathrm{ET}_{\mathrm{A}}$ : $\mathrm{ET}_{\mathrm{B}}$ selectivity $<100$-fold while selective antagonists work on $\mathrm{ET}_{\mathrm{A}}$, thus 


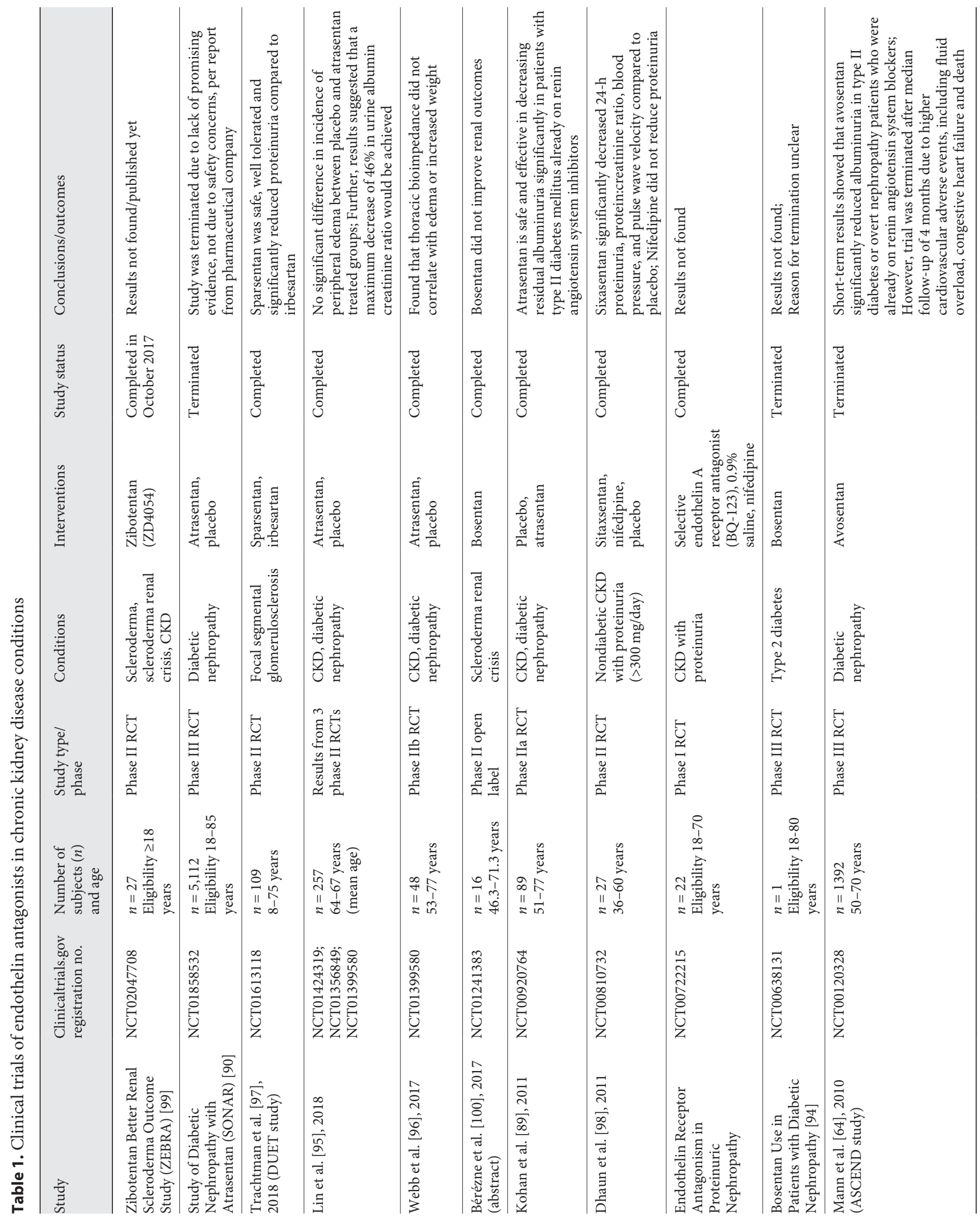


theoretically resulting in less fluid retention. Individual ERAs have specific side effects that must be monitored including hepatotoxicity with patients on sulfonamide-based ERAs [101-103]. $\mathrm{ET}_{\mathrm{A}} / \mathrm{ET}_{\mathrm{B}}$ antagonism is teratogenic, thus contraindicated during pregnancy, but this may be less of a concern in the aging CKD population [21]. Testicular toxicity is another rare, but serious side effect [31]. There are strict patient populations to be avoided due to the many side effects of ERAs including severe CKD and congestive heart failure which may complicate fluid retention management [31]. The "ASCEND" trial tested avosentan but was halted due to the dangerous retention of fluids $[63,64]$. SONAR trial showed good outcomes when ERAs were used with diuretics [90]. Thus, a therapeutic potential may be possible at either lower dosages or if ERA's were utilized in concert with CKD fluid management strategies aimed at ameliorating the dangerous side effects found in this drug class. In addition, any future clinical trials of ERAs for CKD will likely need to include ERA in addition to rather than in place of standard of care, which at present includes an ACEi/ARB, but could potentially be expanded to SGLT2 $\mathrm{i}$ in the near future.

\section{Conclusion}

ETs are a family of potent vasoconstrictors and profibrotic growth factors and its receptors $\left(\mathrm{ET}_{\mathrm{A}}\right.$ and $\left.\mathrm{ET}_{\mathrm{B}}\right)$ are integral in the regulation of renal and cardiovascular pathophysiology. However, ET activation can escalate the progression of CKD and data has suggested that antago- nizing ET may be a promising therapeutic avenue. Multiple studies have shown the utility of ERAs in both diabetic and nondiabetic CKD by reducing blood pressure, proteinuria, and arterial stiffness. However, there have been no studies to date demonstrating that ERAs improve clinical outcomes in CKD. Multiple large clinical trials are needed, and the results of active or recently concluded studies are eagerly awaited for analysis and comparison to current data.

\section{Acknowledgments}

We thank Ms. Jennifer L. Clark, Grant/Medical Writer, Rebecca D. Considine Clinical Research Institute and Akron Children's Hospital for her assistance in language editing.

\section{Disclosure Statement}

The authors have no conflicts of interest to disclose and the results in this paper have not been published previously in whole or part.

\section{Funding Sources}

There are no funding sources to declare.

\section{Author Contributions}

All authors have equally contributed to this paper.

\section{References}

1 Yanagisawa M, Kurihara H, Kimura S, Tomobe Y, Kobayashi M, Mitsui Y, et al. A novel potent vasoconstrictor peptide produced by vascular endothelial cells. Nature. 1988 Mar; 332(6163):411-5.

2 Kohan DE, Rossi NF, Inscho EW, Pollock DM. Regulation of blood pressure and salt homeostasis by endothelin. Physiol Rev. 2011 Jan;91(1):1-77.

3 Barton M, Shaw S, d'Uscio LV, Moreau P, Lüscher TF. Angiotensin II increases vascular and renal endothelin-1 and functional endothelin converting enzyme activity in vivo: role of ETA receptors for endothelin regulation. Biochem Biophys Res Commun. 1997 Sep; 238(3):861-5.

$4 \mathrm{Xu} \mathrm{D}$, Emoto N, Giaid A, Slaughter C, Kaw S, deWit D, et al. ECE-1: a membrane-bound metalloprotease that catalyzes the proteolytic activation of big endothelin-1. Cell. 1994 Aug; 78(3):473-85
5 Ohnaka K, Takayanagi R, Nishikawa M, Haji $M$, Nawata H. Purification and characterization of a phosphoramidon-sensitive endothelin-converting enzyme in porcine aortic endothelium. OFF. J Biol Chem. 1993 Dec: 268(35):26759-66.

6 Takahashi M, Matsushita Y, Iijima Y, Tanzawa K. Purification and characterization of endothelin-converting enzyme from rat lung. J Biol Chem. 1993 Oct;268(28):21394-8.

7 Dhaun N, Goddard J, Webb DJ. The endothelin system and its antagonism in chronic kidney disease. J Am Soc Nephrol. 2006 Apr; 17(4):943-55.

8 Culshaw GJ, MacIntyre IM, Dhaun N, Webb DJ. Endothelin in nondiabetic chronic kidney disease: preclinical and clinical studies. Semin Nephrol. 2015 Mar;35(2):176-87.
9 Ge Y, Bagnall A, Stricklett PK, Strait K, Webb DJ, Kotelevtsev Y, et al. Collecting duct-specific knockout of the endothelin $\mathrm{B}$ receptor causes hypertension and sodium retention. Am J Physiol Renal Physiol. 2006 Dec; 291(6):F1274-80.

10 Ong AC, Jowett TP, Firth JD, Burton S, Kitamura M, Fine LG. Human tubular-derived endothelin in the paracrine regulation of renal interstitial fibroblast function. Exp Nephrol. 1994 Mar-Apr;2(2):134.

11 Gómez-Garre D, Ruiz-Ortega M, Ortego M, Largo R, López-Armada MJ, Plaza JJ, et al. Effects and interactions of endothelin-1 and angiotensin II on matrix protein expression and synthesis and mesangial cell growth. Hypertension. 1996 Apr;27(4):885-92.

12 Haynes WG, Webb DJ. Contribution of endogenous generation of endothelin-1 to basal vascular tone. Lancet. 1994 Sep;344(8926): $852-4$. 
13 Barton M, Yanagisawa M. Endothelin: 20 years from discovery to therapy. Can J Physiol Pharmacol. 2008 Aug;86(8):485-98.

14 Schneider MP, Mann JF. Endothelin antagonism for patients with chronic kidney disease: still a hope for the future. Nephrol Dial Transplant. 2014 Feb;29(Suppl 1):i69-73.

15 Kitamura K, Tanaka T, Kato J, Ogawa T, Eto $\mathrm{T}$, Tanaka K. Immunoreactive endothelin in rat kidney inner medulla: marked decrease in spontaneously hypertensive rats. Biochem Biophys Res Commun. 1989 Jul;162(1):3844.

16 Wesson DE. Endothelin role in kidney acidification. Semin Nephrol. 2006 Sep;26(5):393-

17 Denton KM, Shweta A, Finkelstein L, Flower RL, Evans RG. Effect of endothelin-1 on regional kidney blood flow and renal arteriole calibre in rabbits. Clin Exp Pharmacol Physiol. 2004 Aug;31(8):494-501.

18 Chun M, Lin HY, Henis YI, Lodish HF. Endothelin-induced endocytosis of cell surface ETA receptors. Endothelin remains intact and bound to the ETA receptor. J Biol Chem. 1995 May;270(18):10855-60.

19 Speed JS, Pollock DM. Endothelin, kidney disease, and hypertension. Hypertension. 2013 Jun;61(6):1142-5.

20 Hocher B, Thöne-Reineke C, Rohmeiss P, Schmager F, Slowinski T, Burst V, et al. Endothelin-1 transgenic mice develop glomerulosclerosis, interstitial fibrosis, and renal cysts but not hypertension. J Clin Invest. 1997 Mar; 99(6):1380-9.

21 Kohan DE. Endothelin, hypertension and chronic kidney disease: new insights. Curr Opin Nephrol Hypertens. 2010 Mar; 19(2): 134-9.

22 Ge Y, Bagnall A, Stricklett PK, Webb D, Kotelevtsev Y, Kohan DE. Combined knockout of collecting duct endothelin A and B receptors causes hypertension and sodium retention. Am J Physiol Renal Physiol. 2008 Dec; 295(6):F1635-40.

23 Herrera M, Garvin JL. Endothelin stimulates endothelial nitric oxide synthase expression in the thick ascending limb. Am J Physiol Renal Physiol. 2004 Aug;287(2):F231-5.

24 Plato CF, Pollock DM, Garvin JL. Endothelin inhibits thick ascending limb chloride flux via ET(B) receptor-mediated NO release. Am J Physiol Renal Physiol.2000 Aug;279(2):F32633.

25 Uchida S, Takemoto F, Ogata E, Kurokawa K. Detection of endothelin-1 mRNA by RT-PCR in isolated rat renal tubules. Biochem Biophys Res Commun. 1992 Oct;188(1):108-13.

26 Kohan DE. Endothelin synthesis by rabbit renal tubule cells. Am J Physiol. 1991 Aug;261(2 Pt 2):F221-6.

27 Chen M, Todd-Turla K, Wang WH, Cao X, Smart A, Brosius FC, et al. Endothelin-1 mRNA in glomerular and epithelial cells of kidney. Am J Physiol. 1993 Oct;265(4 Pt 2):F542-50.
28 Ujiie K, Terada Y, Nonoguchi H, Shinohara M, Tomita K, Marumo F. Messenger RNA expression and synthesis of endothelin-1 along rat nephron segments. J Clin Invest. 1992 Sep; 90(3):1043-8

29 Pupilli C, Brunori M, Misciglia N, Selli C, Ianni L, Yanagisawa M, et al. Presence and distribution of endothelin-1 gene expression in human kidney. Am J Physiol. 1994 Oct;267(4 Pt 2):F679-87.

30 Kohan DE. Endothelins in the normal and diseased kidney. Am J Kidney Dis. 1997 Jan; 29(1):2-26.

31 Kohan DE, Barton M. Endothelin and endothelin antagonists in chronic kidney disease. Kidney Int. 2014 Nov;86(5):896-904.

32 Czopek A, Moorhouse R, Webb DJ, Dhaun N. Therapeutic potential of endothelin receptor antagonism in kidney disease. Am J Physiol Regul Integr Comp Physiol. 2016 Mar; 310(5):R388-97.

33 Pernow J, Franco-Cereceda A, Matran R, Lundberg JM. Effect of endothelin-1 on regional vascular resistances in the pig. J Cardiovasc Pharmacol. 1989;13 Suppl 5:S205-6.

34 De Miguel C, Speed JS, Kasztan M, Gohar EY, Pollock DM. Endothelin-1 and the kidney: new perspectives and recent findings. Curr Opin Nephrol Hypertens. 2016 Jan;25(1):3541.

35 Taniguchi M, Yoshida H. Endoplasmic reticulum stress in kidney function and disease. Curr Opin Nephrol Hypertens. 2015 Jul; 24(4):345-50

36 De Miguel C, Hamrick WC, Hobbs JL, Pollock DM, Carmines PK, Pollock JS. Endothelin receptor-specific control of endoplasmic reticulum stress and apoptosis in the kidney. Sci Rep. 2017 Feb;7(1):43152.

37 Jesmin S, Shimojo N, Yamaguchi N, Mowa $\mathrm{CN}$, Oki M, Zaedi S, et al. Effects of protease activated receptor (PAR)2 blocking peptide on endothelin-1 levels in kidney tissues in endotoxemic rat mode. Life Sci. 2014 May; 102(2):127-33.

38 Liu J, Huang K, Cai GY, Chen XM, Yang JR, Lin LR, et al. Receptor for advanced glycation end-products promotes premature senescence of proximal tubular epithelial cells via activation of endoplasmic reticulum stressdependent p21 signaling. Cell Signal. 2014 Jan;26(1):110-21.

39 Noh MR, Kim JI, Han SJ, Lee TJ, Park KM. C/ EBP homologous protein (CHOP) gene deficiency attenuates renal ischemia/reperfusion injury in mice. Biochim Biophys Acta. 2015 Sep;1852(9):1895-901.

40 Sagar SK, Zhang C, Guo Q, Yi R; Lin-Tang. Role of expression of endothelin- 1 and angiotensin-II and hypoxia-inducible factor-1 $\alpha$ in the kidney tissues of patients with diabetic nephropathy. Saudi J Kidney Dis Transpl. 2013 Sep;24(5):959-64.
41 Yang CC, Yao CA, Yang JC, Chien CT. Sialic acid rescues repurified lipopolysaccharideinduced acute renal failure via inhibiting TLR4/PKC/gp91-mediated endoplasmic reticulum stress, apoptosis, autophagy, and pyroptosis signaling. Toxicol Sci. 2014 Sep; 141(1):155-65.

42 Yang D, Yang D, Jia R, Tan J. Na+/Ca2+ exchange inhibitor, KB-R7943, attenuates contrast-induced acute kidney injury. J Nephrol. 2013 Sep-Oct;26(5):877-85.

43 Yang Y, Yang D, Yang D, Jia R, Ding G. Role of reactive oxygen species-mediated endoplasmic reticulum stress in contrast-induced renal tubular cell apoptosis. Nephron, Exp Nephrol. 2014;128(1-2):30-6.

44 Zager RA, Johnson AC, Andress D, Becker K. Progressive endothelin-1 gene activation initiates chronic/end-stage renal disease following experimental ischemic/reperfusion injury. Kidney Int. 2013 Oct;84(4):703-12.

45 Egido J, Rojas-Rivera J, Mas S, Ruiz-Ortega M, Sanz AB, Gonzalez Parra E, et al. Atrasen$\tan$ for the treatment of diabetic nephropathy. Expert Opin Investig Drugs. 2017 Jun;26(6): 741-50.

46 Barutta F, Bellini S, Mastrocola R, Bruno G, Gruden G. MicroRNA and Microvascular Complications of Diabetes. Int J Endocrinol. 2018 Mar;2018:6890501.

47 Yamauchi T, Ohnaka K, Takayanagi R, Umeda F, Nawata H. Enhanced secretion of endothelin-1 by elevated glucose levels from cultured bovine aortic endothelial cells. FEBS Lett. 1990 Jul;267(1):16-8.

48 Morigi M, Buelli S, Angioletti S, Zanchi C, Longaretti L, Zoja C, et al. In response to protein load podocytes reorganize cytoskeleton and modulate endothelin-1 gene: implication for permselective dysfunction of chronic nephropathies. Am J Pathol. 2005 May;166(5): 1309-20.

49 Wu Y, Zhou BP. Snail: more than EMT. Cell Adhes Migr. 2010 Apr-Jun;4(2):199-203.

50 Buelli S, Rosanò L, Gagliardini E, Corna D, Longaretti L, Pezzotta A, et al. $\beta$-arrestin-1 drives endothelin-1-mediated podocyte activation and sustains renal injury. J Am Soc Nephrol. 2014 Mar;25(3):523-33.

51 Rebibou JM, He CJ, Delarue F, Peraldi MN, Adida C, Rondeau E, et al. Functional endothelin 1 receptors on human glomerular podocytes and mesangial cells. Nephrol Dial Transplant. 1992;7(4):288-92.

52 Chen HC, Guh JY, Shin SJ, Tsai JH, Lai YH. Reactive oxygen species enhances endothelin-1 production of diabetic rat glomeruli in vitro and in vivo. J Lab Clin Med. 2000 Apr; 135(4):309-15.

53 Saleh MA, De Miguel C, Stevens DI, Carmines PK, Pollock DM, Pollock JS. Free radical scavenging decreases endothelin-1 excretion and glomerular albumin permeability during type 1 diabetes. Physiol Rep. 2016 Dec; $4(24): 4$ 
54 Breyer MD, Susztak K. Developing Treatments for Chronic Kidney Disease in the 21st Century. Semin Nephrol. 2016 Nov;36(6): 436-47.

55 Boels MG, Avramut MC, Koudijs A, Dane MJ, Lee DH, van der Vlag J, et al. Atrasentan Reduces Albuminuria by Restoring the Glomerular Endothelial Glycocalyx Barrier in Diabetic Nephropathy. Diabetes. 2016 Aug; 65(8):2429-39.

56 Vaneckova I, Hojna S, Kadlecova M, Vernerova Z, Kopkan L, Cervenka L, et al. Renoprotective effects of ET(A) receptor antagonists therapy in experimental non-diabetic chronic kidney disease: Is there still hope for the future? Physiol Res. 2018 Jun;67(Suppl 1):S5567.

57 Garsen M, Lenoir O, Rops AL, Dijkman HB, Willemsen B, van Kuppevelt TH, et al. Endothelin-1 Induces Proteinuria by HeparanaseMediated Disruption of the Glomerular Glycocalyx. J Am Soc Nephrol. 2016 Dec;27(12) 3545-51.

58 Seccia TM, Caroccia B, Gioco F, Piazza M, Buccella V, Guidolin D, et al. Endothelin-1 Drives Epithelial-Mesenchymal Transition in Hypertensive Nephroangiosclerosis. J Am Heart Assoc. 2016 Jul;5(7):1-7.

59 Meyer MR, Barton M, Prossnitz ER. Functional heterogeneity of NADPH oxidase-mediated contractions to endothelin with vascular aging. Life Sci. 2014 Nov;118(2):226-31.

60 Mennuni S, Rubattu S, Pierelli G, Tocci G, Fofi C, Volpe M. Hypertension and kidneys: unraveling complex molecular mechanisms underlying hypertensive renal damage. J Hum Hypertens. 2014 Feb;28(2):74-9.

61 Kimura K, Ohkita M, Koyama M, Matsumura Y. Reduced NO production rapidly aggravates renal function through the NF- $\mathrm{KB} /$ ET-1/ETA receptor pathway in DOCA-saltinduced hypertensive rats. Life Sci. 2012 Oct; 91(13-14):644-50.

62 Baltatu OC, Zaugg CE, Schumacher C, Louie $\mathrm{P}$, Campos LA, Bader M. Avosentan is protective in hypertensive nephropathy at doses not causing fluid retention. Pharmacol Res. 2014 Feb;80:9-13.

63 Hoekman J, Lambers Heerspink HJ, Viberti G, Green D, Mann JF, de Zeeuw D. Predictors of congestive heart failure after treatment with an endothelin receptor antagonist. Clin J Am Soc Nephrol. 2014 Mar;9(3):490-8.

64 Mann JF, Green D, Jamerson K, Ruilope LM, Kuranoff SJ, Littke T, et al.; ASCEND Study Group. Avosentan for overt diabetic nephropathy. J Am Soc Nephrol. 2010 Mar; 21(3):527-35.

65 Saran R, Li Y, Robinson B, Ayanian J, Balkrishnan R, Bragg-Gresham J, et al. US Renal Data System 2014 Annual Data Report: Epidemiology of Kidney Disease in the United States. Am J Kidney Dis. 2015 Jul;66(1 Suppl 1):Svii, S1-305.
66 Kiffel J, Rahimzada Y, Trachtman H. Focal segmental glomerulosclerosis and chronic kidney disease in pediatric patients. Adv Chronic Kidney Dis. 2011 Sep;18(5):332-8.

67 Sadowski CE, Lovric S, Ashraf S, Pabst WL, Gee HY, Kohl S, et al.; SRNS Study Group. A single-gene cause in $29.5 \%$ of cases of steroidresistant nephrotic syndrome. J Am Soc Nephrol. 2015 Jun;26(6):1279-89.

68 Reiser J, Nast CC, Alachkar N. Permeability factors in focal and segmental glomerulosclerosis. Adv Chronic Kidney Dis. 2014 Sep; 21(5):417-21.

69 Daehn I, Casalena G, Zhang T, Shi S, Fenninger F, Barasch N, et al. Endothelial mitochondrial oxidative stress determines podocyte depletion in segmental glomerulosclerosis. J Clin Invest. 2014 Apr;124(4):1608-21.

70 Gipson DS, Chin H, Presler TP, Jennette C, Ferris ME, Massengill S, et al. Differential risk of remission and ESRD in childhood FSGS. Pediatr Nephrol. 2006 Mar;21(3):344-9.

71 Einollahi B, Lotfiazar A. The modifiers of chronic kidney disease in autosomal dominant polycystic kidney disease and the role of the endothelin-1. J Nephropharmacol. 2016 Jan;5(1):24-5.

72 Harris PC, Torres VE. Polycystic kidney disease. Annu Rev Med. 2009;60(1):321-37.

73 Hocher B, Zart R, Schwarz A, Vogt V, Braun C, Thöne-Reineke C, et al. Renal endothelin system in polycystic kidney disease. J Am Soc Nephrol. 1998 Jul;9(7):1169-77.

74 Ong AC, Newby LJ, Dashwood MR. Expression and cellular localisation of renal endothelin-1 and endothelin receptor subtypes in autosomal-dominant polycystic kidney disease. Nephron, Exp Nephrol. 2003;93(2):e806.

75 Dhaun N, Lilitkarntakul P, Macintyre IM, Muilwijk E, Johnston NR, Kluth DC, et al. Urinary endothelin-1 in chronic kidney disease and as a marker of disease activity in lupus nephritis. Am J Physiol Renal Physiol. 2009 Jun;296(6):F1477-83.

76 Munemura C, Uemasu J, Kawasaki H. Epidermal growth factor and endothelin in cyst fluid from autosomal dominant polycystic kidney disease cases: possible evidence of heterogeneity in cystogenesis. Am J Kidney Dis. 1994 Oct;24(4):561-8.

77 Raina R, Lou L, Berger B, Vogt B, Do AS, Cunningham $R$, et al. Relationship of urinary endothelin-1 with estimated glomerular filtration rate in autosomal dominant polycystic kidney disease: a pilot cross-sectional analysis. BMC Nephrol. 2016 Feb;17(1):22.

78 Merta M, Reiterová J, Rysavá R, Tesar V, Závada J, Jáchymová $\mathrm{M}$, et al. Role of endothelin and nitric oxide in the pathogenesis of arterial hypertension in autosomal dominant polycystic kidney disease. Physiol Res. 2003; 52(4):433-7.
79 Chang MY, Parker E, El Nahas M, Haylor JL, Ong AC. Endothelin B receptor blockade accelerates disease progression in a murine model of autosomal dominant polycystic kidney disease. J Am Soc Nephrol. 2007 Feb; 18(2):560-9.

80 Chang MY, Ong AC. New treatments for autosomal dominant polycystic kidney disease. Br J Clin Pharmacol. 2013 Oct;76(4):524-35.

81 Soroka S, Alam A, Bevilacqua M, Girard LP, Komenda P, Loertscher R, et al. Assessing Risk of Disease Progression and Pharmacological Management of Autosomal Dominant Polycystic Kidney Disease: A Canadian Expert Consensus. Can J Kidney Health Dis. 2017 Mar;4:2054358117695784.

82 Walz G, Budde K, Mannaa M, Nürnberger J, Wanner C, Sommerer C, et al. Everolimus in patients with autosomal dominant polycystic kidney disease. N Engl J Med. 2010 Aug; 363(9):830-40

83 Liu YM, Shao YQ, He Q. Sirolimus for treatment of autosomal-dominant polycystic kidney disease: a meta-analysis of randomized controlled trials. Transplant Proc. 2014 JanFeb;46(1):66-74.

84 Caroli A, Perico N, Perna A, Antiga L, Brambilla P, Pisani A, et al.; ALADIN study group. Effect of longacting somatostatin analogue on kidney and cyst growth in autosomal dominant polycystic kidney disease (ALADIN): a randomised, placebo-controlled, multicentre trial. Lancet. 2013 Nov;382(9903):1485-95.

85 Hogan MC, Masyuk TV, Page LJ, Kubly VJ, Bergstralh EJ, Li X, et al. Randomized clinical trial of long-acting somatostatin for autosomal dominant polycystic kidney and liver disease. J Am Soc Nephrol. 2010 Jun;21(6):1052-61.

86 Hogan MC, Masyuk TV, Page L, Holmes DR 3rd, Li X, Bergstralh EJ, et al. Somatostatin analog therapy for severe polycystic liver disease: results after 2 years. Nephrol Dial Transplant. 2012 Sep;27(9):3532-9.

87 Torres VE, Chapman AB, Devuyst O, Gansevoort RT, Grantham JJ, Higashihara E, et al.; TEMPO 3:4 Trial Investigators. Tolvaptan in patients with autosomal dominant polycystic kidney disease. N Engl J Med. 2012 Dec; 367(25):2407-18

88 Krishnappa V, Vinod P, Deverakonda D, Raina R. Autosomal dominant polycystic kidney disease and the heart and brain. Cleve Clin J Med. 2017 Jun;84(6):471-81.

89 Kohan DE, Pritchett Y, Molitch M, Wen S, Garimella T, Audhya P, et al. Addition of atrasentan to renin-angiotensin system blockade reduces albuminuria in diabetic nephropathy. J Am Soc Nephrol. 2011 Apr;22(4):763-72.

90 Heerspink HJ, Parving HH, Andress DL, Bakris G, Correa-Rotter R, Hou FF, et al.; SONAR Committees and Investigators. Atrasentan and renal events in patients with type 2 diabetes and chronic kidney disease (SONAR): a doubleblind, randomised, placebo-controlled trial. Lancet. 2019 May;393(10184):1937-47. 
91 Heerspink HJ, Andress DL, Bakris G, Brennan JJ, Correa-Rotter R, Dey J, et al. Rationale and protocol of the Study Of diabetic Nephropathy with AtRasentan (SONAR) trial: A clinical trial design novel to diabetic nephropathy. Diabetes Obes Metab. 2018 Jun;20(6): 1369-76.

92 Heerspink HJ, Andress DL, Bakris G, Brennan JJ, Correa-Rotter R, Hou FF, et al. Baseline characteristics and enrichment results from the SONAR trial. Diabetes Obes Metab. 2018 Aug;20(8):1829-35.

93 Woo JL. AbbVie Closes SONAR Study Evaluating Investigational Compound Atrasentan on Renal Outcomes in Patients with Diabetic Nephropathy. Online, AbbVie, 2017.

94 ChdlUdM (CHUM): Bosentan Use in Patients with Diabetic Nephropathy. 2010.

95 Lin CW, Mostafa NM, L Andress D, J Brennan J, Klein CE, Awni WM. Relationship Between Atrasentan Concentrations and Urinary Albumin to Creatinine Ratio in Western and Japanese Patients With Diabetic Nephropathy. Clin Ther. 2018 Feb;40(2):242-51.
96 Webb DJ, Coll B, Heerspink HJ, Andress D, Pritchett Y, Brennan JJ, et al. Longitudinal Assessment of the Effect of Atrasentan on Thoracic Bioimpedance in Diabetic Nephropathy: A Randomized, Double-Blind, PlaceboControlled Trial. Drugs R D. 2017 Sep;17(3): 441-8.

97 Trachtman H, Nelson P, Adler S, Campbell KN, Chaudhuri A, Derebail VK, et al.; DUET Study Group. DUET: A Phase 2 Study Evaluating the Efficacy and Safety of Sparsentan in Patients with FSGS. J Am Soc Nephrol. 2018 Nov;29(11):2745-54.

98 Dhaun N, MacIntyre IM, Kerr D, Melville V, Johnston NR, Haughie S, et al. Selective endothelin-A receptor antagonism reduces proteinuria, blood pressure, and arterial stiffness in chronic proteinuric kidney disease. Hypertension. 2011 Apr;57(4):772-9.
99 Ohnishi A, Orita Y, Okahara R, Fujihara H, Inoue $\mathrm{T}$, Yamamura $\mathrm{Y}$, et al. Potent aquaretic agent. A novel nonpeptide selective vasopressin 2 antagonist (OPC-31260) in men. J Clin Invest. 1993 Dec;92(6):2653-9.

100 Bérezné A, Karras A, Marie I, Huart A, Ficheux M, Queyrel V, et al. Bosentan in Scleroderma Renal Crisis: A National Open Label Prospective Study [abstract]. Arthritis Rheumatol. 2017;69(suppl 10).

101 Doumas M, Athyros V, Katsiki N, Reklou A Lazaridis A, Karagiannis A. Endothelin Receptor Antagonists (ERA) in Hypertension and Chronic Kidney Disease a Rose with Many Thorns. Open Hypertens J. 2013;5(1): 12-7.

102 Hoeper MM. Liver toxicity: the Achilles' heel of endothelin receptor antagonist therapy? Eur Respir J. 2009 Sep;34(3):529-30.

103 Hoeper MM, Olsson KM, Schneider A, Golpon H. Severe hepatitis associated with sitaxentan and response to glucocorticoid therapy. Eur Respir J. 2009 Jun;33(6): $1518-9$. 